\author{
AUS DEM LEHRSTUHL \\ FÜR ANÄSTHESIOLOGIE \\ PROF. DR. BERNHARD M. GRAF, Msc. \\ DER FAKULTÄT FÜR MEDIZIN \\ DER UNIVERSITÄT REGENSBURG
}

Hypoactive Delirium After Cardiac Surgery as an Independent Risk Factor for Prolonged Mechanical Ventilation

\author{
Inaugural - Dissertation \\ zur Erlangung des Doktorgrades \\ der Medizin
}

der

Fakultät für Medizin

der Universität Regensburg

vorgelegt von

Melanie Karin Stransky 



\author{
AUS DEM LEHRSTUHL \\ FÜR ANÄSTHESIOLOGIE \\ PROF. DR. BERNHARD M. GRAF, Msc. \\ DER FAKULTÄT FÜR MEDIZIN \\ DER UNIVERSITÄT REGENSBURG
}

Hypoactive Delirium After Cardiac Surgery as an Independent Risk Factor for Prolonged Mechanical Ventilation

\author{
Inaugural - Dissertation \\ zur Erlangung des Doktorgrades \\ der Medizin
}

der

Fakultät für Medizin

der Universität Regensburg

vorgelegt von

Melanie Karin Stransky 
Dekan:

1. Berichterstatter:

2. Berichterstatter:

Tag der mündlichen Prüfung:
Prof. Dr. Dr. Torsten E. Reichert PD Dr. Benedikt Trabold PD Dr. Daniele Camboni 21.05.12 


\title{
Hypoactive Delirium After Cardiac Surgery as an Independent Risk Factor for Prolonged Mechanical Ventilation
}

\author{
Melanie Stransky,* Christoph Schmidt, MD, $\neq$ Patrycja Ganslmeier, MD, $†$ Elmar Grossmann, MD, $\neq$ \\ Assad Haneya, MD, $†$ Stefan Moritz, MD, $\neq$ Michael Raffer, MD,* Christof Schmid, PhD, $†$ \\ Bernhard M. Graf, PhD,* and Benedikt Trabold, MD*
}

\begin{abstract}
Objective: The authors' intention was to evaluate the incidence of the three subtypes of delirium, the risk factors of the subtypes in cardiac surgery, and the impact of the subtypes on clinical outcomes.

Design: A prospective study.

Setting: A university hospital.

Participants: A total population of 506 patients undergoing cardiac surgery was screened for delirium.

Interventions: None.

Measurement and Main Results: Patients undergoing cardiac surgery were screened by using the Intensive Care Delirium Screening Checklist (ICDSC) and the Richmond Agitation and Sedation Scale (RASS). Patients with hypoactive delirium were compared with nondelirious patients. Outcomes measured were the duration of mechanical ventilation and the length of stay in the intensive care unit. The overall delirium incidence was $11.6 \%$, whereas the incidence of the hypoactive subtype was $9 \%$. Age (odds ratio [OR] 1.04; 95\% confidence interval $[\mathrm{Cl}], 1.01-1.09, p=0.02$ ), a history of depression $(\mathrm{OR}=3.57 ; 95 \% \mathrm{Cl}, 1.04-10.74 ; p=$
\end{abstract}

D ELIRIUM IS A common and significant problem because it is associated with increased mortality, longer intensive care unit (ICU) and hospital stays and a longer duration of mechanical ventilation. ${ }^{1,2}$ Because pharmacologic treatments for delirium have not been successful, the focus of current scientific efforts has shifted from treatment of this syndrome to prevention. Recent studies have attempted to outline the general pathophysiology and risk factors of delirium. The etiology of delirium is multifactorial, and the number of factors that contribute to its development varies among patients. ${ }^{3}$ Many parameters have been examined to determine their association with delirium, and these investigations have yielded conflicting results.

In cardiac surgery, postoperative delirium is a serious problem because of its high incidence and its impact on clinical outcomes. ${ }^{4}$ Recently, investigators have identified several risk factors for postoperative delirium. For example, postoperative delirium in cardiac surgery is associated with older age, a history of depression, abnormal sodium and potassium values, anemia, and the type of surgery..$^{5-7}$ Although some of these factors cannot be modified, others could be used for preventive care. ${ }^{8,9}$

From the Departments of *Anesthesiology; and + Cardiothoracic Surgery, University Hospital Regensburg, Regensburg, Germany; and $¥$ Department of Anesthesiology, University Hospital Halle, Halle, Germany.

Address reprint requests to Benedikt Trabold, MD, Department of Anesthesiology, University Hospital Regensburg, Franz-Josef-Strauss Allee 11, 93053 Regensburg, Germany. E-mail: benedikt.trabold@ klinik.uni-regensburg.de

(C) 2011 Elsevier Inc. All rights reserved.

1053-0770/2506-0011\$36.00/0

doi:10.1053/j.jvca.2011.05.004
0.03 ), preoperative therapy with diuretics (OR $=2.85$; $95 \%$ $\mathrm{Cl}$, 1.36-6.35; $p<0.01$ ), aortic clamping times (OR $=1.01$; 95\% Cl, 1.00-1.02; $p<0.01$ ) and blood transfusions (OR = $1.18 ; 95 \% \mathrm{Cl}, 1.05-1.34 ; p<0.01$ ) were predictors for the development of hypoactive delirium. Preoperative therapy with $\beta$-blockers (OR $=0.32 ; 95 \% \mathrm{Cl}, 0.16-0.65 ; p<0.01$ ) and higher hemoglobin before surgery $(\mathrm{OR}=0.73 ; 95 \% \mathrm{Cl}, 0.60$ $0.91 ; p<0.01$ ) were associated with a lower prevalence of hypoactive delirium. Hypoactive delirium is an independent predictor for prolonged mechanical ventilation time (OR = $1.56 ; 95 \% \mathrm{Cl}, 1.25-1.92 ; p<0.01)$ and the length of stay in the ICU (OR = 1.42; 95\% Cl, 1.22-1.65, $p<0.01)$.

Conclusion: Hypoactive delirium itself is a strong predictor for a longer ICU stay and a prolonged period of mechanical ventilation. Some of the risk factors related to the intraoperative and postoperative setting are suitable for preventive action.

(C) 2011 Elsevier Inc. All rights reserved.

KEY WORDS: hypoactive delirium, cardiac surgery, risk factors, Intensive Care Delirium Screening Checklist

By using a standardized delirium assessment method, such as the Intensive Care Delirium Screening Checklist (ICDSC) or the Confusion Assessment Method for Intensive Care (CAM-ICU), and the Richmond Agitation-Sedation Scale (RASS), delirium can be divided into 3 subtypes: hypoactive, hyperactive, and a combination of both types (mixed form). ${ }^{10-13}$ According to O'Keeffe and Lavan, ${ }^{14}$ the subtypes can be identified from the patient's pattern of psychomotor activity and alertness. Hypoactive delirium is characterized by unawareness, decreased alertness, lethargy, and decreased motor activity. The symptoms of hyperactive delirium are hypervigilance, restlessness, irritability, combativeness, and distractibility. The mixed type of delirium represents a combination of criteria for both types. ${ }^{15}$ It can be assumed that each delirium subtype has a special etiology and, therefore, a unique set of risk factors. ${ }^{16}$ Although patients with encephalopathy usually have hypoactive delirium, pharmacologically-induced delirium typically is hyperactive. ${ }^{14}$ Studies that analyze these special risk factors for each subtype in cardiac surgery patients currently are lacking. Because early intervention could influence the incidence of cardiac surgery-associated delirium, it is of the utmost importance to detect these relevant predicting factors.

The authors tested the hypothesis that the risk factors and the impact of the outcome of delirium differ among the delirium subtypes. Therefore, the present study was designed to determine the incidence of postoperative early-onset delirium and its subtypes after cardiac surgery using the ICDSC and the RASS. The second aim was to identify risk factors for the development of the subtypes of delirium and the impacts of the subtypes on clinical outcomes.

\section{MATERIALS AND METHODS}

After approval by the local Ethics Committee, all patients undergoing cardiac surgery in the authors' clinic were screened after admission to the ICU between May 2008 and November 2008. The requirement 
for informed consent was waived by the Ethics Committee. Patients who were readmitted to the ICU, patients who were comatose during the first 3 postoperative days, and patients who were deeply sedated and could not be examined neurologically were excluded. The definitions of comatose patients and deep sedation were determined based on a RASS score from -4 to -5 and based on ICDSC scoring.

Standard surgical and anesthesia techniques were used for all patients. After the induction of anesthesia with fentanyl, etomidate, and pancuronium, anesthesia was maintained with sevoflurane and supplemented with bolus doses of fentanyl and pancuronium. Cardiopulmonary bypass was performed according to standard techniques for conventional extracorporeal circulation (ECC) and a miniaturized extracorporeal circulation (MECC; MAQUET Cardiopulmonary AG, Hirrlingen, Germany) system (mean arterial pressure $>60 \mathrm{mmHg}$, blood flow $2.5 \mathrm{~L} / \mathrm{min} / \mathrm{m}^{2}$, temperature $33^{\circ}-34^{\circ} \mathrm{C}$ ). The MECC system is a closed, preconnected extracorporeal system that contains a diffusion membrane oxygenator and centrifugal pump. The ECC consisted of a roller pump, a diffusion membrane oxygenator, and a hard-shell venous reservoir. Cardiac arrest was induced with a modified Calafiore cardioplegia solution. The postoperative procedures were identical for all patients. Postoperative sedation was performed with propofol and fentanyl or sufentanil. The dosage of opioids was expressed as morphine equivalents. Once patients' body temperature reached $36^{\circ} \mathrm{C}$ and their condition was satisfactory, sedation was ceased, and extubation was accomplished.

The delirium assessment of all included patients was conducted during the first 3 postoperative days (including patients who had left the ICU) with the aid of the ICDSC and the Behavioral Pain Scale (BPS) because pain has been associated with delirium. The ICDSC is an 8 -item screening tool that circumvents the communicative limitations of ICU patients. The evaluation process included an assessment of consciousness, inattention, orientation, the presence of hallucinations or delusions, psychomotor agitation, inappropriate speech or mood, sleep cycle disturbances, and symptom fluctuations. Every manifestation of an item counted as 1 point. In cases of coma, the evaluation was cancelled. Therefore, patients with endotracheal tubes were evaluated as long as they were able to respond. During every evaluation, the BPS was assessed, and delirium evaluation did not proceed until the BPS was $<5$ points. Patients with an ICDSC score of 4 or higher were considered delirious, and those with a score of 3 or less were classified as nondelirious (Appendix 1). Sedation and the delirium subtype were assessed with the RASS (Appendix 2). All delirious patients with RASS scores from -3 to 0 were considered hypoactive, and those with scores from 1 to 4 were considered hyperactive. Patients with hyperactive and hypoactive symptoms on different days were considered to have mixed delirium. The assessment was performed daily by physicians who were trained to use the ICDSC and RASS.

The selection of the possible risk factors was based on clinical judgment and previous investigations. Risk factors were grouped according to the corresponding time period as pre-, intra-, and postoperative factors. The first category contained preoperative and predisposing factors, such as age, sex, comorbidities (eg, infections, diabetes, chronic heart diseases, chronic airway diseases, renal insufficiency, renal replacement therapy, pre-existing neurologic diseases, smoking, and alcoholism), preoperative medication (eg, $\beta$-blockers, diuretics, and anticoagulant agents), selected laboratory values (ie, creatinine, bilirubin, sodium, potassium, and hemoglobin), hemodynamic values (mean arterial pressure [MAP], heart rate, and echocardiographic ejection fraction), and the EuroSCORE. ${ }^{17}$ The EuroSCORE is a method of calculating predicted operative mortality for patients undergoing cardiac surgery (www.euroscore.org). This information was obtained from patients and their medical records.

In the intraoperative category, the type and duration of surgery, the type and duration of extracorporeal circulation, and selected laboratory (sodium, potassium, hemoglobin, $\mathrm{pO}_{2}, \mathrm{pCO}_{2}$, lactate, and glucose) and he- modynamic values (MAP and heart rate) were recorded. The parameters were gathered before, during, and at the end of the operation. The most variant value was recorded in the database. As a severity of disease classification system, the Acute Physiology and Chronic Health Evaluation II (APACHE II) was used to assess patients upon their arrival in the ICU. ${ }^{18}$ Selected postoperative laboratory (ie, creatinine, bilirubin, sodium, potassium, hemoglobin, $\mathrm{pO}_{2}, \mathrm{pCO}_{2}$, lactate, and glucose) and hemodynamic (ie MAP, heart rate, and cardiac output) values were collected daily, and the number of units of packed red blood cells transfused was noted. The transfusion decision was based on the patient's clinical condition and the judgment of the treating physician. The creatinine and bilirubin values were obtained upon arrival in the ICU and every morning for the first 3 postoperative days. Heart rate, MAP, and $\mathrm{SpO}_{2}$ were recorded continuously, whereas the other parameters were recorded every 4 hours. The most variant value was listed in the database. The study also included postoperative complications, such as infections (diagnosed by a leukocyte count $>12,000 / \mathrm{mm}^{3}$ and fever $>38.0^{\circ} \mathrm{C}$ ), cardiac surgery-associated acute kidney injury (according to Mehta et $\mathrm{al}^{19}$ ), revision operations (because of bleeding or cardiac tamponade), and respiratory insufficiency (defined as arterial hypoxemia $\left[\mathrm{pO}_{2}<50 \mathrm{mmHg}\right]$ and hypercarbia $\left[\mathrm{pCO}_{2}\right.$ $>50 \mathrm{mmHg}]$ ). At discharge from the hospital, the adverse outcome variables assessed consisted of the length of the ICU stay and the duration of mechanical ventilation (by standardized criteria of extubation). Furthermore, mortality data 5 months after surgery were collected.

All hypoactive delirious patients (with an ICDSC score of 4 or higher at least once and a RASS score from -3 to 0 ) were compared with those without delirium (with an ICDSC score of 3 or less). The sample size was selected based on previous studies and included the records of 500 patients. ${ }^{7,20}$ Furthermore, the minimum sample size per group was calculated based on the method described by Julious. ${ }^{21}$ Because previous studies have shown that age is an independent risk factor for delirium, the results of the age parameter from Koster et $\mathrm{al}^{7}$ were used to calculate the minimum sample size per group. Descriptive statistics (percentages for categoric data and means and standard deviations for continuous data) were used to examine the demographic characteristics of the study population. The baseline characteristics and the disease and laboratory variables between the hypoactive delirious patients and the nondelirious patients were compared using the independent sample $t$ test or the Wilcoxon rank-sum test for continuous variables and the chi-square or Fisher exact test (if the total sample size was $<10$ ) for categoric variables. Univariate regression analyses were used for the selection of variables. Parameters with a $p$ value $<0.05$ were included in multiple stepwise regression analyses. Factors with a prevalence of $<10 \%$ in the hypoactive delirious group were not used for multiple regression analysis.

A multiple linear stepwise regression analysis model was used to identify the independent predictors of the outcome parameters (the length of ICU stay and the duration of mechanical ventilation). Five explanatory variables (sex, EuroSCORE, APACHE II, extracorporeal circulation, and hypoactive delirium) were chosen based on clinical judgment and previous investigations. Because histograms of the ICU stay and the duration of mechanical ventilation showed a skewed distribution, the data were transformed using a log scale. Analyses were performed using R (R Project for Statistical Computing, R Development Core Team, www.R-project.org). A $p$ value $<0.05$ was considered to be statistically significant.

\section{RESULTS}

A total of 506 patients were screened. Because 39 patients were excluded because of coma or deep sedation, 467 patients ultimately were included; 42 patients were classified as hypoactive delirium, 6 as hyperactive delirium, and 6 as mixed delirium. Because the incidence of hyperactive delirium and the mixed form was too low for statistical analysis, the patients 
were divided into 2 groups depending on whether they developed hypoactive delirium (42 patients) or no delirium (413 patients). Thirty-two patients displayed symptoms of hypoactive delirium on the 1 st postoperative day. On the 2 nd postoperative day, 8 patients exhibited the first signs of hypoactive delirium, whereas on the $3 \mathrm{rd}$ postoperative day, only 4 patients showed symptoms of hypoactive delirium for the first time.

The preoperative variables are presented in Table 1 . The average age of the patients with hypoactive delirium was 71.1 years compared with 66.4 in the group of patients without delirium $(p=$ $0.01)$. The group of patients with hypoactive delirium included significantly more women than the nondelirium group $(p=0.02)$. The ratio of a history of depression was higher in the hypoactive delirium group than in the nondelirium group $(p=0.04)$. Approximately $42.9 \%$ of the patients with hypoactive delirium were receiving therapy with $\beta$-blockers compared with $62 \%$ of patients without delirium $(p<0.01)$. Patients with hypoactive delirium had undergone preoperative therapy with diuretics more often than the nondelirium group $(p=0.02)$. The EuroSCORE was significantly higher in the group of patients with hypoactive delirium, as was the incidence of emergency surgery $(p=0.02)$. Other preoperative variables, particularly parameters of renal or liver impairment, did not show any statistically significant differences between the hypoactive delirium group and the group without delirium.

Overall, $14 \%$ of patients with hypoactive delirium underwent aortic surgery compared with $5 \%$ of patients without delirium $(p<0.01)$. The choice and type of extracorporeal circulation were not related to the incidence of hypoactive delirium. Although the duration of surgery did not differ significantly between the groups, the duration of aortic clamping $(p=0.01)$ and the time to reperfusion $(p=0.02)$ were significantly prolonged in the group of patients with hypoactive delirium. Furthermore, there was a significant difference between the lowest hemoglobin level before cardiopulmonary bypass $(p=0.01)$ and the highest lactate level during the operation $(p=0.01)$.

In contrast to the 1 st and 2 nd postoperative days, the immediate postoperative hemoglobin value differed significantly between the groups $(p=0.04)$. The differences between the groups' sodium and potassium values were significant throughout the entire postoperative period (Table 2). The glucose value on the 2 nd postoperative day differed significantly between the groups $(p=0.01)$. Lactate values differed significantly throughout the entire postoperative period, except on the 3rd postoperative day. Hemodynamic and respiratory variables showed no significant differences on any postoperative days, and all other values did not differ significantly on the 3rd postoperative day (data not shown). Patients with hypoactive delirium received more packed red blood cells than patients without delirium $(p<0.01)$. Moreover, the incidence of postoperative complications, such as CSA-AKI $(p<0.01)$, infections $(p=0.02)$, or revision $(p=0.03)$, was significantly higher in the group of patients with hypoactive delirium. Only $16.6 \%$ of the patients with hypoactive delirium were discharged to home compared with $44.1 \%$ of the patients without hypoactive delirium $(p<0.01)$. Mortality was higher in the group of patients with hypoactive delirium $(p=0.04)$.

Variables deemed significant based on the univariate analysis were subjected consecutively to stepwise logistic regression analysis. The preoperative variables of age, history of depression, and preoperative therapy with diuretics were identified as independent predictors of postoperative hypoactive delirium. The variable emergency surgery was not an independent predictor of delirium. Furthermore, the duration of aortic clamping

Table 1. Pre- and Intraoperative Variables

\begin{tabular}{|c|c|c|c|c|}
\hline & Hypoactive Delirium & No Delirium & $p$ Value & $\begin{array}{l}\text { Univariate Regression Analysis } \\
\text { OR }(95 \% \mathrm{Cl})\end{array}$ \\
\hline \multicolumn{5}{|l|}{ Preoperative } \\
\hline Female sex $(\%)$ & $17(40.5)$ & $97(23,5)$ & 0.02 & $0.45(0.23-0.87)$ \\
\hline Age (y) & $71.1 \pm 10.5$ & $66.4 \pm 10.3$ & 0.01 & $1.05(1.02-1.09)$ \\
\hline Depression (\%) & $5(11.9)$ & $17(4.1)$ & 0.03 & $3.35(1.16-9.67)$ \\
\hline Beta-blocker preoperative (\%) & $18(42.9)$ & $277(67.0)$ & $<0.01$ & $0.37(0.19-0.70)$ \\
\hline Diuretics preoperative (\%) & $29(69.0)$ & $207(50.1)$ & 0.02 & $2.21(1.12-4.37)$ \\
\hline EuroSCORE & $12.0 \pm 11.8$ & $7.4 \pm 9.3$ & $<0.01$ & $1.04(1.01-1.06)$ \\
\hline Emergency surgery (\%) & $6(14.3)$ & $24(5.8)$ & 0.04 & $2.69(1.03-7.02)$ \\
\hline \multicolumn{5}{|l|}{ Intraoperative } \\
\hline Aortic surgery (\%) & $6(14.3)$ & $21(5.0)$ & 0.02 & $2.96(1.13-7.78)$ \\
\hline Valvular surgery (\%) & $20(42.5)$ & $285(69.0)$ & 0.11 & $1.68(0.88-3.12)$ \\
\hline CABG & $25(59.5)$ & $275(66.5)$ & 0.34 & $0.73(038-1.39)$ \\
\hline \multicolumn{5}{|l|}{ Extracorporeal circulation (\%) } \\
\hline ECC & $31(73.8)$ & $252(61.0)$ & 0.09 & $1.84(0.90-3.76)$ \\
\hline MECC & $6(14.3)$ & $103(24.9)$ & 0.12 & $0.50(0.20-1.21)$ \\
\hline OPCAB & $5(11.9)$ & $58(14.0)$ & 0.67 & $0.81(0.31-2.15)$ \\
\hline Duration of surgery (min) & $200.6 \pm 61.5$ & $185.4 \pm 55.4$ & 0.09 & $1.00(1.00-1.01)$ \\
\hline Duration of aortic clamping (min) & $81.1 \pm 43.3$ & $62.4 \pm 30.1$ & 0.01 & $1.01(1.01-1.02)$ \\
\hline Time of reperfusion (min) & $33.5 \pm 17.7$ & $26.9 \pm 14.9$ & 0.02 & $1.02(1.00-1.04)$ \\
\hline Hemoglobin before ECC (g/dL) & $11.9 \pm 1.8$ & $12.6 \pm 1.7$ & 0.01 & $0.79(0.66-0.95)$ \\
\hline Lactate (mg/dL) & $26.8 \pm 25.8$ & $18.4 \pm 15.9$ & 0.01 & $1.02(1.01-1.03)$ \\
\hline
\end{tabular}

NOTE. All data were presented as mean \pm standard deviation.

Abbreviations: CABG, coronary artery bypass graft; OPCAB, off-pump coronary artery bypass; OR, odds ratio; Cl, confidence interval. 
Table 2. Postoperative Variables

\begin{tabular}{|c|c|c|c|c|}
\hline & Hypoactive Delirium & No Delirium & $p$ Value & $\begin{array}{c}\text { Univariate Regression Analysis } \\
\text { OR }(95 \% \mathrm{Cl})\end{array}$ \\
\hline \multicolumn{5}{|l|}{ Postoperative } \\
\hline Hemoglobin (g/dL) & $9.2 \pm .9$ & $9.5 \pm 1.0$ & 0.04 & $0.69(0.49-0.99)$ \\
\hline Potassium (mmol/L) & $5.1 \pm 0.7$ & $4.9 \pm 0.5$ & 0.02 & $2.01(1.08-3.72)$ \\
\hline Sodium (mmol/L) & $140.1 \pm 4.7$ & $138.2 \pm 4.4$ & 0.01 & $1.09(1.02-1.16)$ \\
\hline Glucose (mg/dL) & $108.3 \pm 23.3$ & $116.4 \pm 34.8$ & 0.14 & $0.99(0.97-1.00)$ \\
\hline Lactate (md/dL) & $32.5 \pm 31.7$ & $22.6 \pm 19.3$ & 0.03 & $1.02(1.00-1.03)$ \\
\hline \multicolumn{5}{|l|}{ 1st day postoperative } \\
\hline Hemoglobin (g/dL) & $10.2 \pm 1.1$ & $10.3 \pm 1.1$ & 0.51 & $0.90(0.67-1.21)$ \\
\hline Potassium (mmol/L) & $5.2 \pm 0.5$ & $4.9 \pm 0.5$ & $<0.01$ & $3.33(1.72-6.43)$ \\
\hline Sodium (mmol/L) & $140.9 \pm 4.8$ & $137.9 \pm 4.5$ & $<0.01$ & $1.14(1.06-1.22)$ \\
\hline Glucose (mg/dL) & $104.8 \pm 25.7$ & $116.8 \pm 28.3$ & 0.01 & $0.98(0.96-0.99)$ \\
\hline Lactate (mg/dL) & $22.7 \pm 14.3$ & $17.3 \pm 13$ & 0.01 & $1.02(1.00-1.04)$ \\
\hline \multicolumn{5}{|l|}{ 2nd day postoperative } \\
\hline Hemoglobin (g/dL) & $10.0 \pm 1.2$ & $10.4 \pm 1.2$ & 0.09 & $0.77(0.58-1.04)$ \\
\hline Potassium (mmol/L) & $4.8 \pm 0.5$ & $4.7 \pm 0.4$ & 0.02 & $2.23(1.10-4.51)$ \\
\hline Sodium (mmol/L) & $137.9 \pm 4.8$ & $136.0 \pm 4.2$ & 0.01 & $1.10(1.04-1.18)$ \\
\hline Glucose (mg/dL) & $115.1 \pm 46.5$ & $128.4 \pm 41.2$ & 0.05 & $0.98(0.97-1.00)$ \\
\hline Lactate (mg/dL) & $17.9 \pm 10.6$ & $15.1 \pm 7.9$ & 0.04 & $1.03(0.99-1.06)$ \\
\hline APACHE II & $14.3 \pm 6.1$ & $11.3 \pm 4.7$ & $<0.01$ & $1.11(1.05-1.18)$ \\
\hline Units of PRBCs (mean) & $3.2 \pm 3.8$ & $1.6 \pm 2.2$ & $<0.01$ & $1.20(1.08-1.34)$ \\
\hline Equivalence dose of morphine $(\mathrm{mg} / \mathrm{d})$ & $10.6 \pm 13.7$ & $10.3 \pm 10.1$ & 0.85 & $1.00(0.97-1.03)$ \\
\hline Propofol (mg/h) & $242.6 \pm 75.7$ & $219.2 \pm 80.0$ & 0.07 & $1.04(1.00-1.08)$ \\
\hline CSA AKI (\%) & $20(47.6)$ & 99 (23.9) & $<0.01$ & $2.88(1.51-5.50)$ \\
\hline Revision (\%) & $7(16,6)$ & $35(8,5)$ & 0.03 & $1.11(1.00-1.22)$ \\
\hline Infection (\%) & $4(9.5)$ & $9(2.2)$ & 0.02 & $4.72(1.39-6.06)$ \\
\hline Duration of ventilation (hours) & $37.0 \pm 78.6$ & $13.1 \pm 15.6$ & $<0.01$ & $1.01(1.00-1.02)$ \\
\hline ICU stay $(d)$ & $5.6 \pm 4.8$ & $3.1 \pm 3.4$ & $<0.01$ & $1.14(1.04-1.25)$ \\
\hline Discharge home & $7(16.6)$ & $182(44,1)$ & $<0.01$ & $1.59(1.14-2.21)$ \\
\hline Mortality (\%) & $4(9.5)$ & $11(2.7)$ & 0.04 & 3.87 (1.16-12.67) \\
\hline
\end{tabular}

NOTE. All data were presented as mean \pm standard deviation.

Abbreviations: PRBCs, packed red blood cells; OR, odds ratio; $\mathrm{Cl}$, confidence interval.

and blood transfusion were found to be independent predictors of postoperative hypoactive delirium. As Table 3 shows, 2 variables were associated with a significantly lower prevalence of hypoactive delirium. Of note, preoperative therapy with $\beta$-blockers had a protective effect against hypoactive delirium.

As Table 2 shows, the time on mechanical ventilation was

Table 3. Multiple Logistic Regression Model: Predictors of Hypoactive Delirium

\begin{tabular}{lccc}
\hline & \multicolumn{3}{c}{ Stepwise Logistic Regression } \\
& Analysis \\
\cline { 2 - 4 } & $p$ Value & OR & $95 \% \mathrm{Cl}$ \\
\hline Age (y) & 0.02 & 1.04 & $1.01-1.09$ \\
Depression (\%) & 0.03 & 3.57 & $1.04-10.74$ \\
Diuretics preoperative (\%) & $<0.01$ & 2.85 & $1.36-6.35$ \\
Duration of aortic & $<0.01$ & 1.01 & $1.00-1.02$ \\
$\quad$ clamping (min) & & & \\
Units of PRBCs & $<0.01$ & 1.18 & $1.05-1.34$ \\
$\beta$-Blocker preoperative (\%) & $<0.01$ & 0.32 & $0.16-0.65$ \\
Higher hemoglobin before & $<0.01$ & 0.73 & $0.60-0.91$ \\
$\quad$ surgery (g/dL) & & & \\
$R^{2}=0.12$ & & & \\
\hline
\end{tabular}

Abbreviations: PRBCs, packed red blood cells; OR, odds ratio; $\mathrm{Cl}$, confidence interval; $R^{2}$, adjusted coefficient of determination. significantly longer in the group of patients with hypoactive delirium. Furthermore, patients with hypoactive delirium stayed longer in the ICU than patients without delirium. The stepwise multiple linear regression model identified hypoactive delirium and APACHE II as independent predictors of prolonged mechanical ventilation in this investigation. However, surgery without extracorporeal circulation was associated with a significantly lower prevalence of prolonged ventilation (Table 4). Although hypoactive delirium, EuroSCORE and APACHE II were independent predictors of the length of the ICU stay, surgery without extracorporeal circulation was associated with a significantly shorter duration of stay in the ICU (Table 5).

Table 4. Multiple Linear Regression Model: Predictors of the Duration of Ventilation

\begin{tabular}{|c|c|c|c|}
\hline & \multicolumn{3}{|c|}{ Stepwise Linear Regression Analysis } \\
\hline & $p$ Value & OR & $95 \% \mathrm{Cl}$ \\
\hline Hypoactive delirium & $<0.01$ & 1.55 & $1.25-1.92$ \\
\hline OPCAB & $<0.01$ & 0.84 & $0.77-0.92$ \\
\hline APACHE II & $<0.01$ & 1.03 & $1.01-1.04$ \\
\hline$R^{2}=0.16$ & & & \\
\hline
\end{tabular}

Abbreviations: OR, odds ratio; $\mathrm{Cl}$, confidence interval; $R^{2}$, adjusted coefficient of determination. 


\section{DISCUSSION}

The overall incidence of delirium was $11.6 \%$ in the present study. This figure falls well within the previously established range of 5\% to $30 \%$ reported by previous cardiac surgery studies. ${ }^{4,22}$ The incidence of the hypoactive subtype was $8.99 \%$. In the present study, nearly $80 \%$ of all delirious patients were assigned to the hypoactive subtype, whereas previous studies in geriatric units have found hyperactive or mixed forms of delirium in most cases. ${ }^{14}$ One reason for the high incidence of hypoactive delirium in this study may have been the use of a standardized screening method for the delirium subtypes. Clinical assessment alone results in a lower incidence of postoperative delirium diagnoses, particularly of hypoactive delirium. ${ }^{23,24}$

Because delirium evaluation should be incorporated easily into the daily routines of hospital staff, the CAM-ICU and the ICDSC are appropriate for evaluating patients in the ICU. Although the CAM-ICU requires the patient to answer several questions, the ICDSC necessitates no cooperation by the patient. For these reasons, it is possible that false diagnoses of delirium occur with the CAM-ICU in sedated patients. ${ }^{25}$ Furthermore, the ICDSC has displayed a higher specificity and positive predictive value than the CAM-ICU in a mixed ICU. ${ }^{26}$ In addition, the assessment of consciousness and psychomotor retardation by the ICDSC may enable a better recognition of hypoactive delirium. ${ }^{25}$

Age was identified as an independent risk factor for the development of hypoactive delirium. Old age is a well-known risk factor for any type of delirium in cardiac surgery. 22,27 The EuroSCORE was not significant in the multiple regression analysis although it was described as a risk factor for cardiac surgery-associated delirium in a previous study. ${ }^{7}$ Because the EuroSCORE is a summation of preoperative risk factors and these risk factors are not predictors of hypoactive delirium, the EuroSCORE was not a predictor in the present study. Several studies have shown a history of depression as a predictor of delirium after cardiac surgery. ${ }^{6,28}$ The present study was the first to show that a history of depression is also a predictor of hypoactive delirium after cardiac surgery. The present results revealed that preoperative medication with diuretics was a predictor of hypoactive delirium, whereas medication with $\beta$-blockers was associated with a significantly lower prevalence of hypoactive delirium. Although the pathophysiology of psychomotor hyperactive delirium could be explained by a dopamine-acetylcholine neurotransmitter imbalance, the pathophysiology of hypoactive delirium likely involves other neurotransmitter systems. ${ }^{29,30}$ Therefore, pharmacologic interactions with neurotransmitters differ between the types of delirium, and medications such as diuretics or $\beta$-blockers show different efficacies as predictors of the type of delirium.

The duration of aortic clamping was a strong predictor of cardiac surgery-associated hypoactive delirium in the present study. This result may indicate that a prolonged duration of extracorporeal circulation is associated with an increased risk of neurologic injury caused by cerebral ischemia or inflammation and a higher rate of gaseous and particulate microemboli. ${ }^{27,31}$ According to the present results, the type of extracorporeal circulation (ECC or MECC) or its avoidance (off-pump coronary artery bypass) did not influence the occurrence of hypoactive delirium. This result is consistent with previous studies on postoperative cognitive dysfunction. ${ }^{32}$ The authors speculated that the duration of extracorporeal circulation and surgery, not the choice of extracorporeal circulation or its avoidance, was the major determinant of the incidence of postoperative delirium. Consistent with previous studies, the type of surgical procedure was not an independent predictor of hypoactive delirium in the present investigation. ${ }^{6,33}$ In contrast, several studies have shown that cardiac valve surgery results in a higher incidence of delirium than coronary artery bypass surgery. ${ }^{5,34}$ Although this discrepancy may be caused by a different study design, further investigation is necessary to resolve this issue.

Consistent with previous findings, the perioperative rate of blood transfusion was an independent predictor of hypoactive delirium, whereas higher preoperative hemoglobin values indicated a lower prevalence of hypoactive delirium. ${ }^{8}$ A higher volume of intraoperative blood loss may be responsible for the higher transfusion rate and thus for the increased risk of hypoxemia in the central nervous system. ${ }^{35}$

Identifying patients with a higher risk for developing delirium is critical for reducing the incidence of delirium and enabling specific perioperative measures such as choice of medication and prophylactic interventions. Although preoperative risk factors, such as age and a history of depression, enable proactive intervention strategies, intraoperative risk factors (eg, aortic clamping time and blood transfusion) facilitate early postoperative multicomponent intervention to prevent postoperative delirium. ${ }^{36,37}$

A further aim of this study was to identify the hypoactive subtype of postoperative delirium as an independent predictor of outcome variables, such as prolonged duration of mechanical ventilation and longer ICU stay, using multiple linear regression analyses. The use of extracorporeal circulation and the incidence of postoperative hypoactive delirium increased the duration of mechanical ventilation. The authors suggest that the prolonged duration of mechanical ventilation in patients with hypoactive delirium is caused by limited consciousness and limited coordination between the respiratory system and the brain, leading to a longer time of rehabilitation. Although delirium already has been described as an independent predictor of prolonged duration of ventilation, the present results showed, for the first time, that hypoactive delirium is an independent predictor.

Hypoactive delirium and high scores on the EuroSCORE and APACHE II were independent predictors of increased ICU stay. The significance of hypoactive delirium on increased ICU stay after cardiac survey was shown for the first time in this

Table 5. Multiple Linear Regression Model: Predictors of Length of Stay in ICU

\begin{tabular}{lccc}
\hline & \multicolumn{3}{c}{ Stepwise Linear Regression } \\
\cline { 2 - 4 } & $p$ Value & OR & $95 \% \mathrm{Cl}$ \\
\hline Hypoactive delirium & $<0.01$ & 1.41 & $1.21-1.65$ \\
OPCAB & $<0.01$ & 0.91 & $0.86-0.97$ \\
EuroSCORE & 0.03 & 1.00 & $1.00-1.01$ \\
APACHE II & $<0.01$ & 1.03 & $1.02-1.04$ \\
$R^{2}=0.15$ & & & \\
\hline
\end{tabular}

Abbreviations: $\mathrm{OR}$, odds ratio; $\mathrm{Cl}$, confidence interval; $R^{2}$, adjusted coefficient of determination. 
study. Identifying these 3 risk factors for a prolonged ICU stay is important because such patients require much more attention from health personnel and more intensive therapy.

This investigation had several limitations. The criteria for inclusion resulted in a mixed population of cardiac surgery patients. Therefore, the study group was not treated entirely uniformly. The low incidence of hyperactive delirium and mixed-form delirium in the present population, compared with previous studies, did not allow the authors to draw conclusions about risk factors for these subtypes. The authors attempted to form a logical and comprehensive statistical model based on pre-, intra-, and postoperative factors. The individual effect of a single factor in the onset of hypoactive delirium after cardiac surgery was difficult to extract because all of the factors interacted in a complex way. The design of a predictive model based on a single factor excludes many related factors. When comparing this report to further studies using other delirium screening tools, the delirium assessment (ICDSC and RASS) and the criteria for inclusion must be noted.

\section{CONCLUSION}

This research outlined the risk factors, which were divided into pre-, intra- and postoperative factors, for hypoactive delirium after cardiac surgery. Multiple risk factors included patients' age, history of depression, preoperative diuretics, duration of aortic clamping, and the number of blood transfusions. However, higher hemoglobin levels before surgery and preoperative therapy with $\beta$-blockers were associated with a significantly lower prevalence of hypoactive delirium. Some of these factors can be used to develop preventive approaches. Hypoactive delirium is itself a strong independent predictor of the duration of mechanical ventilation and a longer ICU stay after cardiac surgery. Therefore, further investigations into the prevention and therapy of hypoactive delirium are necessary. The present results suggested that delirium screening after cardiac surgery and the differentiation of the hypoactive, hyperactive, and mixed subtypes is essential. These findings are the basis for future research on the risk factors of the hyperactive and mixed delirium subtypes.

\section{APPENDIX 1: INTENSIVE CARE DELIRIUM SCREENING CHECKLIST ${ }^{10}$}

The scale was completed based on information collected from each 8-hour shift or from the previous 24 hours. Obvious manifestation of an item $=1$ point; no manifestation of an item or no assessment possible $=0$ points. The score of each item ( 0 or 1$)$ was entered in the corresponding empty box.

1. Altered level of consciousness:

(A) No response or (B) the need for vigorous stimulation to obtain any response signified a severe alteration in the level of consciousness that precluded evaluation. If there was coma (A) or stupor (B) most of the time, a dash (-) was entered, and there was no further evaluation during that period.

(C) Drowsiness or requirement for mild-to-moderate stimulation for a response implied an altered level of consciousness and scored 1 point.

(D) Wakefulness or a sleeping state from which the patient could be easily aroused was considered normal and scored no points.
(E) Hypervigilance was rated as an abnormal level of consciousness and scored 1 point.

2. Inattention:

Difficulty in following a conversation or instructions, easy distraction by external stimuli, or difficulty in shifting focus scored 1 point.

3. Disorientation:

Any obvious mistake in time, place or person scored 1 point.

4. Hallucination, delusion or psychosis:

The unequivocal clinical manifestation of hallucination or behavior that was likely caused by hallucination or delusion (eg, trying to catch a nonexistent object) or gross impairment in reality testing scored 1 point.

5. Psychomotor agitation or retardation:

Hyperactivity requiring the use of additional sedative drugs or restraints to control potential danger to oneself or others (eg, pulling out intravenous lines or hitting staff), hypoactivity, or clinically noticeable psychomotor slowing scored 1 point.

6. Inappropriate speech or mood:

Inappropriate, disorganized, or incoherent speech or inappropriate display of emotion related to events or situation scored 1 point.

7. Sleep/wake cycle disturbance:

Sleeping $<4$ hours or waking frequently at night (wakefulness initiated by the medical staff or loud environment was not considered) or sleeping during most of the day scored 1 point.

8. Symptom fluctuation:

Fluctuations in the manifestation of any item or symptom over 24 hours (eg, from one shift to another) scored 1 point.

APPENDIX 2: RICHMOND AGITATION-SEDATION SCALE ${ }^{13}$

\begin{tabular}{|c|c|c|}
\hline Score & Term & Description \\
\hline+4 & Combative & $\begin{array}{l}\text { Overtly combative, violent, } \\
\text { immediate danger to staff }\end{array}$ \\
\hline+3 & Very agitated & $\begin{array}{l}\text { Pulls or removes tube(s) or } \\
\text { catheter(s); aggressive }\end{array}$ \\
\hline+2 & Agitated & $\begin{array}{l}\text { Frequent but not purposeful } \\
\text { movement, fights } \\
\text { ventilator }\end{array}$ \\
\hline+1 & Restless & $\begin{array}{l}\text { Anxious but movements not } \\
\text { aggressive or vigorous }\end{array}$ \\
\hline 0 & Alert and calm & \\
\hline-1 & Drowsy & $\begin{array}{l}\text { Not fully alert but has } \\
\text { sustained awakening (eye- } \\
\text { opening/eye contact) to } \\
\text { voice ( } \geq 10 \text { seconds) }\end{array}$ \\
\hline-2 & Lightly sedated & $\begin{array}{l}\text { Briefly awakens with eye } \\
\text { contact to voice }(<10 \\
\text { seconds) }\end{array}$ \\
\hline-3 & Moderately sedated & $\begin{array}{l}\text { Movement or eye opening to } \\
\text { voice (but no eye contact) }\end{array}$ \\
\hline-4 & Deeply sedated & $\begin{array}{l}\text { No response to voice but } \\
\text { movement or eye opening } \\
\text { to physical stimulation }\end{array}$ \\
\hline-5 & Unarousable & $\begin{array}{l}\text { No response to voice or } \\
\text { physical stimulation }\end{array}$ \\
\hline
\end{tabular}




\section{REFERENCES}

1. Ceriana P, Fanfulla F, Mazzacane F, et al: Delirium in patients admitted to a step-down unit: analysis of incidence and risk factors. J Crit Care 25:136-143, 2010

2. Robinson TN, Raeburn CD, Tran ZV, et al: Postoperative delirium in the elderly: Risk factors and outcomes. Ann Surg 249:173-178, 2009

3. Van Rompaey B, Elseviers MM, Schuurmans MJ, et al: Risk factors for delirium in intensive care patients: A prospective cohort study. Crit Care 13:R77, 2009

4. Sockalingam S, Parekh N, Bogoch II, et al: Delirium in the postoperative cardiac patient: A review. J Card Surg 20:560-567, 2005

5. Hudetz JA, Iqbal Z, Gandhi SD, et al: Postoperative delirium and short-term cognitive dysfunction occur more frequently in patients undergoing valve surgery with or without coronary artery bypass graft surgery compared with coronary artery bypass graft surgery alone: Results of a pilot study. J Cardiothorac Vasc Anesth July 21, 2010 [Epub ahead of print]

6. Kazmierski J, Kowman M, Banach M, et al: Incidence and predictors of delirium after cardiac surgery: Results from the IPDACS study. J Psychosom Res 69:179-185, 2010

7. Koster S, Oosterveld FGJ, Hensens AG, et al: Delirium after cardiac surgery and predictive validity of a risk checklist. Ann Thorac Surg 86:1883-1887, 2008

8. Bucerius J, Gummert JF, Borger MA, et al: Predictors of delirium after cardiac surgery delirium: Effect of beating-heart (off-pump) surgery. J Thorac Cardiovasc Surg 127:57-64, 2004

9. Burkhart CS, Dell-Kuster S, Gamberini M, et al: Modifiable and nonmodifiable risk factors for postoperative delirium after cardiac surgery with cardiopulmonary bypass. J Cardiothorac Vasc Anesth 24:555-559, 2010

10. Bergeron N, Dubois MJ, Dumont M, et al: Intensive care delirium screening checklist: Evaluation of a new screening tool. Intensive Care Med 27:859-864, 2001

11. Ely EW, Inouye SK, Bernard GR, et al: Delirium in mechanically ventilated patients: Validity and reliability of the confusion assessment method for the intensive care unit (CAM-ICU). JAMA 286: 2703-2710, 2001

12. Pandharipande P, Cotton BA, Shintani A, et al: Motoric subtypes of delirium in mechanically ventilated surgical and trauma intensive care unit patients. Intensive Care Med 33:1726-1731, 2007

13. Sessler CN, Gosnell MS, Grap MJ, et al: The Richmond agitation-sedation scale: Validity and reliability in adult intensive care unit patients. Am J Respir Crit Care Med 166:1338-1344, 2002

14. O'Keeffe ST, Lavan JN: Clinical significance of delirium subtypes in older people. Age Ageing 28:115-119, 1999

15. Liptzin B, Levkoff SE: An empirical study of delirium subtypes. Br J Psychiatry 161:843-845, 1992

16. Meagher DJ, O'Hanlon D, O’Mahony E, et al: Relationship between symptoms and motoric subtype of delirium. J Neuropsychiatry Clin Neurosci 12:51-56, 2000

17. Nashef SA, Roques F, Michel P, et al: European system for cardiac operative risk evaluation (EuroSCORE). Eur J Cardiothorac Surg 16:9-13, 1999

18. Knaus WA, Draper EA, Wagner DP, et al: APACHE II: A severity of disease classification system. Crit Care Med 13:818-829, 1985
19. Mehta RL, Kellum JA, Shaf SV, et al: Acute kidney injury network: Report of an initiative to improve outcomes in acute kidney injury. Crit Care 11:R31, 2007

20. Ely EW, Shintani A, Truman B, et al: Delirium as a predictor of mortality in mechanically ventilated patients in the intensive care unit. JAMA 291:1753-1762, 2004

21. Julious SA: Sample sizes for clinical trials with normal data. Stat Med 23:1921-1986, 2004

22. Loponen P, Luther M, Wistbacka J, et al: Postoperative delirium and health related quality of life after coronary artery bypass grafting. Scand Cardiovasc J 42:337-344, 2008

23. Meagher DJ, Moran M, Raju B, et al: Motor symptoms in 100 patients with delirium versus control subjects: Comparison of subtyping methods. Psychosomatics 49:300-308, 2008

24. Norkiene I, Ringaitiene D, Misiuriene I, et al: Incidence and precipitating factors of delirium after coronary artery bypass grafting Scand Cardiovasc J 41:180-185, 2007

25. Devlin JW, Fong JJ, Fraser GL, et al: Delirium assessment in the critically ill. Intensive Care Med 33:929-940, 2007

26. van Eijk MMJ, van Marum RJ, Klijn IAM, et al: Comparison of delirium assessment tools in a mixed intensive care unit. Crit Care Med 37:1881-1885, 2009

27. Giltay EJ, Huijskes RVHP, Kho KH, et al: Psychotic symptoms in patients undergoing coronary artery bypass grafting and heart valve operation. Eur J Cardiothorac Surg 30:140-147, 2006

28. Rudolph JL, Jones RN, Levkoff SE, et al: Derivation and validation of a preoperative prediction rule for delirium after cardiac surgery. Circulation 119:229-236, 2009

29. Gaudreau J, Gagnon P: Psychotogenic drugs and delirium pathogenesis: The central role of the thalamus. Med Hypotheses 64:471-475, 2005

30. Maldonado JR: Pathoetiological model of delirium: A comprehensive understanding of the neurobiology of delirium and an evidence-based approach to prevention and treatment. Crit Care Clin 24:789-856, 2008

31. Newman MF, Mathew JP, Grocott HP, et al: Central nervous system injury associated with cardiac surgery. Lancet 368:694-703, 2006

32. van Dijk D, Spoor M, Hijman R, et al: Cognitive and cardiac outcomes 5 years after off-pump vs on-pump coronary artery bypass graft surgery. JAMA 297:701-708, 2007

33. Afonso A, Scurlock C, Reich D, et al: Predictive model for postoperative delirium in cardiac surgical patients. Semin Cardiothorac Vasc Anesth 14:212-217, 2010

34. Ebert AD, Walzer TA, Huth $\mathrm{C}$, et al: Early neurobehavioral disorders after cardiac surgery: A comparative analysis of coronary artery bypass graft surgery and valve replacement. J Cardiothorac Vasc Anesth 15:15-19, 2001

35. Granberg Axèll AIR, Malmros CW, Bergbom IL, et al: Intensive care unit syndrome/delirium is associated with anemia, drug therapy and duration of ventilation treatment. Acta Anaesthesiol Scand 46:726731, 2002

36. Hempenius L, van Leeuwen BL, van Asselt DZ, et al: Structured analyses of interventions to prevent delirium. Int J Geriatr Psychiatry 26:441-450, 2011

37. Marcantonio ER, Flacker JM, Wright RJ, et al: Reducing delirium after hip fracture: A randomized trial. J Am Geriatr Soc 49:516522,2001 


\section{Lebenslauf}

\section{Persönliche Daten}

Name Melanie Karin Stransky

Geburtsdatum, -ort 13.08.1985, Erlangen

Staatsangehörigkeit deutsch

\section{Ausbildung}

09/1992 - 07/1996 Grundschule Neukirchen - Etzelwang

09/1996 - 06/2005 Herzog - Christian - August - Gymnasium, SulzbachRosenberg

10/2005 - 11/2011 Medizinstudium an der Universität Regensburg

Praktisches Jahr

$$
\begin{array}{ll}
08 / 2010-12 / 010 & \text { chirurgische Unterassistenzärztin im Spital Wetzikon, Schweiz } \\
12 / 2010-04 / 2011 & \begin{array}{l}
\text { Innere Medizin im Krankenhaus Barmherzige Brüder, } \\
\text { Regensburg }
\end{array} \\
04 / 2011-07 / 2011 & \text { Anästhesie im Uniklinikum Regensburg }
\end{array}
$$

seit $01 / 2012$

Assistenzärztin an der Klinik für Innere Medizin I im Klinikum St. Elisabeth Straubing 


\section{Danksagung}

Mein besonderer Dank gilt Herrn Dr. Benedikt Trabold, der diese Studie initiierte, sie leitete und mich in jeder Phase der Studie unterstützt.

Danken möchte ich vor allem auch Herrn Dr. Elmar Grossmann, Frau Dr. Patrycia Dryja, Herrn Assad Haneya, Herrn Michael Raffer, Herrn Dr. Christoph Schmidt und Herrn Dr. Benedikt Trabold, die für meine Studie an den ersten drei postoperativen Tagen die Parameter ICDSC, RASS und BPS erhoben. Herzlichen Dank.

Vielen Dank auch an Herrn Stefan Ferstner von der Informatik der HTC.

Erwähnen möchte ich an dieser Stelle auch die Stationen 46, 60, 61, 97 und 93, die mich bei meiner Recherche unterstützten.

Des Weitern gilt mein Dank meinen Eltern und Freunden, darunter möchte ich namentlich Charlotte Dietrich, Katharina Kaser und Miriam Susewind nennen, die diese Arbeit konstruktiv und kritisch begleitet haben. 